\title{
Mechanical ventilation: invasive versus noninvasive
}

\author{
L. Brochard
}

\begin{abstract}
Mechanical ventilation: invasive versus noninvasive. L. Brochard. C ERS Journals Ltd 2003.

ABSTRACT: Mechanical ventilation is the most widely used supportive technique in intensive care units. Several forms of external support for respiration have long been described to assist the failing ventilatory pump, and access to lower airways through tracheostomy or endotracheal tubes had constituted a major advance in the management of patients with respiratory distress. More recently, however, new "noninvasive" ventilation (NIV) techniques, using patient/ventilator interfaces in the form of facial masks, have been designed.

The reasons for promoting NIV include a better understanding of the role of ventilatory pump failure in the indications for mechanical ventilation, the development of ventilatory modalities able to work in synchrony with the patient, and the extensive recognition of complications associated with endotracheal intubation and standard mechanical ventilation.

NIV has been used primarily for patients with acute hypercapnic ventilatory failure, and especially for acute exacerbation of chronic obstructive pulmonary disease. In this population, the use of NIV is associated with a marked reduction in the need for endotracheal intubation, a decrease in complication rate, a reduced duration of hospital stay and a substantial reduction in hospital mortality. Similar benefits have also been demonstrated in patients with asphyxic forms of acute cardiogenic pulmonary oedema. In patients with primarily hypoxemic forms of respiratory failure, the level of success of NIV is more variable, but major benefits have also been demonstrated in selected populations with no contraindications such as multiple organ failure, loss of consciousness or haemodynamic instability.

One important factor in success seems to be the early delivery of noninvasive ventilation during the course of respiratory failure. Noninvasive ventilation allows many of the complications associated with mechanical ventilation to be avoided, especially the occurrence of nosocomial infections. The current use of noninvasive ventilation is growing up, and is becoming a major therapeutic tool in the intensive care unit.

Eur Respir J 2003; 22: Suppl. 47, 31s-37s.
\end{abstract}

Correspondence: L. Brochard Service de Réanimation Médicale Hôpital Henri Mondor 94010 Créteil Cedex France

Fax: 33142079943

E-mail: laurent.brochard@hmn.ap-hop-paris.fr

Keywords: Acute exacerbation of chronic obstructive pulmonary disease endotracheal intubation mechanical ventilation pulmonary oedema

Received: May 62003

Accepted after revision: July 292003
Without mechanical support for respiration, many patients would die within hours to days due to acute hypoxaemic and hypercapnic respiratory failure. Observational, physiological and case/control studies form a large body of evidence demonstrating that noninvasive ventilation (NIV) can be used in many situations to decrease a patient's dyspnoea and work of breathing, improve gas exchange and ultimately avoid the need for endotracheal intubation (ETI) [1-3]. Randomised controlled trials have confirmed this and helped delineate when NIV should be used as a first-line treatment. Studies conducted outside the context of clinical trials are also of great importance in ensuring that the results of these trials can be obtained in real life [4-6]. Indeed, the success of NIV may follow a learning curve, and early results may not be as good as those obtained later. In addition, it must be clear to clinicians that NIV is a complementary technique and cannot replace ETI in all instances.

In theory, the modes and settings for the delivery of NIV could be very similar to those for traditional mechanical ventilation through an endotracheal tube or tracheotomy cannula. In practice, because the circumstances of ventilation are different, the population of patients more selected and the equipment available sometimes more limited, this is not the case. In addition, leaks are a quasiconstant feature of NIV [7, 8]. NIV is usually delivered in the form of assisted ventilation, in which every breath is supported by the ventilator. Rarely, controlled mechanical ventilation is used.

\section{Acute exacerbation of chronic respiratory failure}

Patients with hypercapnic forms of acute respiratory failure are most likely to benefit from NIV [1-3]. Their respiratory muscles become unable to generate adequate alveolar ventilation despite large pressure swings because of the presence of severe abnormalities in respiratory mechanics (intrinsic positive end-expiratory pressure (PEEP) and high inspiratory resistances) [9]. Stimulation of the respiratory centres and the large negative intrathoracic pressure swings generated do not permit compensation for these abnormalities; rapid shallow breathing ensues, associated with carbon dioxide retention and respiratory acidosis, and a risk of respiratory muscle fatigue. Dyspnoea, right ventricular failure and encephalopathy characterise the severe acute exacerbation. Delivery of NIV allows the patient to take deeper breaths with less effort. NIV at two levels of pressure (pressure support [10] and PEEP [11]) delivers a positive inspiratory pressure swing in synchrony with the patient's inspiratory effort. A low level of pressure during expiration counterbalances the effects of dynamic hyperinflation, which 
result in a positive residual alveolar pressure at the end of expiration. The combination of the two levels of pressure has the greatest efficacy in reducing patient effort [12]. NIV can reverse the clinical abnormalities related to hypoxaemia, hypercapnia and acidosis $[9,13]$.

\section{Clinical trials}

The efficacy of NIV in the case of acute exacerbation of chronic obstructive pulmonary disease (COPD) has been extensively studied (table 1 ). A recent international consensus conference recommended that NIV be considered a first-line treatment in these patients [24], and British Thoracic Society guidelines recommend that every hospital should be able to deliver NIV on a round-the-clock basis in this indication [25]. In 1990, a case/control study first demonstrated that NIV could markedly reduce the need for ETI [9]. Subsequently, several prospective randomised trials confirmed that NIV reduces the need for ETI and the rate of complications, shortens the duration of hospital stay and improves survival in patients with COPD [14-16, 18-20, 26]. In a prospective randomised trial, KRAMER et al. [15] found a major reduction in the need for ETI. In this study, 74\% of patients had COPD and the reduction in ETI rate in this group was from 67 to $9 \%$. Two studies, conducted in the UK, demonstrated the efficacy of NIV outside the intensive care unit (ICU) [14, 20]. In the largest study in the ICU, in which 85 patients with COPD were randomised to treatment with or without face mask pressure support ventilation [16], the ETI rate was $74 \%$ for controls receiving standard medical treatment compared to only $26 \%$ in the NIV group. This reduction was associated with fewer complications during the ICU stay, a reduced duration of hospital stay and, more importantly, a significant reduction in mortality rate (from 29 to $9 \%$ ). The overall decrease in mortality was ascribable to reductions in the need for ETI and various ICU-related complications.

Two open studies also described the beneficial short-term effects of using NIV in asthmatic patients deteriorating despite medical therapy [27, 28].

\section{Where to perform noninvasive ventilation}

An early randomised trial in 60 patients performed by BoTT et al. [14] found major benefits of NIV performed in the emergency department or ward on dyspnoea and outcome, especially when the four patients who did not tolerate NIV were excluded from the analysis. A more recent prospective multicentric randomised trial conducted in the UK by PLANT et al. [20] compared standard therapy alone (control group) and with NIV in 236 COPD patients admitted to general respiratory wards due to acute respiratory failure. The failure (reaching criteria for ETI) rate was higher in the control group ( 27 versus $15 \%$ ), and NIV was associated with a lower in-hospital mortality rate. Two specific aspects of this study need to be emphasised in order to explain the results. Owing to admission policy in the UK, all patients who failed NIV were not transferred to an ICU, and, for this reason, the results may not be extrapolated to all kinds of medical institution because the control group might have benefited from a more intensive approach in other institutions. The authors stressed the fact that, for the most severe patients (arterial blood $\mathrm{pH}$ of $<7.30$ on admission), the benefit of delivering NIV outside the ICU became marginal, with a high mortality rate. These patients would probably have benefited from early ICU admission for NIV delivery. The other aspect is the specific teaching and training of personnel before and during the course of the study. A strict protocol was followed during the study, with no individual titration. Very probably, this is a key element in explaining the benefits observed in the study. Other studies performed in emergency departments did not show similar benefits [17, 29], and, in one study, the results even suggested that ETI could have been delayed by inappropriate or inadequate use of NIV [29].

Table 1.-Randomised controlled clinical trials assessing the efficacy of noninvasive ventilation (NIV) in patients with chronic obstructive pulmonary disease (COPD)

\begin{tabular}{|c|c|c|c|}
\hline First author [Ref.] & Patients $n$ & Location/study & Impact of NIV \\
\hline BOTT [14] & 60 & Ward & $\begin{array}{c}\text { Improvement in ABGs, dyspnoea } \\
\text { Reduction in ETI criteria }\end{array}$ \\
\hline KRAMER [15] & 31 (74\% COPD) & ICU & $\begin{array}{c}\text { Reduction in mortality (excluding } 4 \text { patients not on NIV) } \\
\text { Improvement in ABGs, dyspnoea } \\
\text { Reduction in ETI ( } 67 \text { to } 9 \% \text { in COPD) }\end{array}$ \\
\hline BROCHARD [16] & 84 & ICU & $\begin{array}{c}\text { Improvement in ABGs } \\
\text { Reduction in ETI ( } 74 \text { to } 26 \% \text { ), complications, LOS } \\
\text { Reduction in mortality }\end{array}$ \\
\hline BARBÉ [17] & 24 & Emergency ward & No benefit; no ETI required \\
\hline ANGUS [18] & 17 & NIV versus doxapram & Improvement in $\mathrm{ABGs}$ \\
\hline CELIKEL [19] & 30 & - & $\begin{array}{l}\text { Improvement in ABGs } \\
\text { Reduction in criteria for ETI, LOS }\end{array}$ \\
\hline PlanT [20] & 236 & Ward & $\begin{array}{l}\text { Improvement in ABGs } \\
\text { Reduction in criteria for ETI } \\
\text { Reduction in mortality }\end{array}$ \\
\hline CONTI $[21]$ & 49 & Late ICU admission and NIV & $\begin{array}{l}\text { Reduction in ETI (48 to } 100 \%) \\
\text { Similar ICU outcome } \\
\text { Fewer long-term readmissions ( } 65 \text { versus } 100 \% \text { ) }\end{array}$ \\
\hline NAVA [22] & 50 & MV curtailment after $48 \mathrm{~h}$ & $\begin{array}{c}\text { Improvement in weaning success } \\
\text { Reduction of LOS, complications } \\
\text { Reduction in mortality }\end{array}$ \\
\hline GIRAULT [23] & 33 & MV curtailment after $4-5$ days & $\begin{array}{l}\text { Shorter duration of ETI } \\
\text { No change in outcome } \\
\text { Longer duration of ventilation }\end{array}$ \\
\hline
\end{tabular}

ABGs: arterial blood gases; ETI: endotracheal intubation; ICU: intensive care unit; LOS: length of stay; MV: mechanical ventilation. 


\section{Workload for the personnel}

In the study of PLANT et al. [20], the training period comprised $8 \mathrm{~h}$ over the 3 months preceding the study and $1 \mathrm{~h}$ monthly during the trial. Three studies specifically studied the workload for the personnel associated with the use of NIV. They found a different distribution of workload compared to a more traditional approach towards patients with respiratory failure $[15,20,30]$. The first $6-8 \mathrm{~h}$ of NIV are usually associated with a high level of workload, reflecting the need for personnel to remain at the bedside.

\section{When to perform noninvasive ventilation}

Early NIV to prevent further deterioration must become an important part of the first-line therapy of acute exacerbation of COPD [31]. A very low arterial blood $\mathrm{pH}$, marked alteration in mental status when NIV is started, and the presence of comorbid conditions or a high severity score characterise patients who experience NIV failure [1, 32]. The presence of several of these factors seems to indicate that late delivery of NIV during the course of the exacerbation reduces the likelihood of success. Every effort should be made to deliver NIV early, and close monitoring is therefore in order when NIV is started late. In addition, a recent randomised controlled trial indicates that the efficacy of NIV diminishes when this therapy is applied late in the course of the exacerbation. Indeed, CoNTI et al. [21] studied patients at a very late stage, and showed a reduction in ETI from 100 to $52 \%$, which was associated with only marginal short-term benefits. NIV was applied to patients with COPD who had stayed a mean of $14 \mathrm{~h}$ in the emergency ward before being admitted to the ICU, when, before the advent of NIV, ETI and mechanical ventilation would have been the usual treatment. Interestingly, there were still significant long-term benefits associated with the use of NIV, such as a decrease in the readmission rate and the need for long-term oxygen therapy.

\section{Long-term survival}

Three studies have suggested that the use of NIV is associated with a better 1 -yr survival compared to standard ICU therapy [33, 34] or invasive mechanical ventilation [35]. The recent study of CONTI et al. [21] confirms these findings.

\section{Negative pressure ventilation}

Nowadays, the technique of negative pressure ventilation is only available in very few centres in the world. It should be mentioned, however, that negative pressure ventilation was the first mode of delivering noninvasive ventilation, before positive pressure ventilation became the rule in the 1950s [36, 37]. Its efficacy in the treatment of acute exacerbations of COPD may be superior, in experienced hands, to a traditional approach with invasive mechanical ventilation, and similar to noninvasive ventilation via a face mask $[38,39]$.

\section{Helium-oxygen mixture}

The use of a helium/oxygen mixture during NIV seems very promising for further reducing dyspnoea and work of breathing in patients with COPD [40, 41]. Several randomised controlled trials are in progress to test the hypothesis that this gas mixture could increase the success rate of this technique.

\section{Cardiogenic pulmonary oedema}

\section{Pathophysiology}

Continuous positive airway pressure (CPAP) has the ability, by raising intrathoracic pressure, to decrease shunting and improve arterial oxygenation and dyspnoea in patients with acute cardiogenic pulmonary oedema [42-47]. CPAP can both lessen the work of breathing substantially and improve cardiovascular function by decreasing the left ventricular afterload in nonpreload-dependent patients [46]. Pressure support plus PEEP induces similar pathophysiological benefits.

Most patients with cardiogenic pulmonary oedema improve rapidly with medical therapy. A few, however, develop acute asphyxic respiratory distress and require ventilatory support until the medical treatment starts to work. This may be particularly common in elderly patients with heart disease and patients with concomitant chronic lung disease [48]. Several NIV modalities have been tried successfully, the goal being to avoid ETI.

Continuous positive airway pressure or pressure support plus positive end-expiratory pressure

Randomised trials comparing either CPAP or pressure support plus PEEP to standard medical therapy found similar results with the two techniques in terms of improvement in arterial blood gas levels and respiratory frequency. Both CPAP and pressure support plus PEEP significantly reduced the ETI rate $[43,44,47,49,50]$. Two studies, however, indicate a need for caution. One compared pressure support plus PEEP and CPAP [51]. Acute myocardial infarction was more common in the pressure support group than in the CPAP group and it remains unclear whether this should be ascribed to a randomisation bias or to a deleterious effect of pressure support plus PEEP itself. A high rate of acute myocardial infarction was not found in the NIV arm of a randomised controlled trial with pressure support and PEEP, nor in observational studies [47, 49, 50]. The second study compared intravenous bolus therapy with high-dose nitrates to conventional medical therapy (a different medical therapy) and pressure support plus PEEP. The first of these two treatments was far more clinically effective than NIV and resulted in a better outcome [52]. These two studies draw attention to the vulnerability of patients with cardiogenic pulmonary oedema, particularly those with ischaemic heart disease. They indicate that both appropriate drug therapy and close monitoring are in order when using any form of NIV, especially in patients with ischaemic heart disease.

\section{Hypoxaemic respiratory failure}

Positive pressure ventilation was reintroduced during the first half of the twentieth century, for support of patients requiring general anaesthesia for surgery, especially thoracic procedures. When the earliest case series of patients with adult respiratory distress syndrome were reported in the late 1960s [53], positive pressure ventilation was used with increasing frequency for nonsurgical patients with acute respiratory failure of various causes, including obstructive airways disease and severe pneumonia. NIV was proposed, in the early 1990s, for treating these patients, but initial studies have not all been successful [27, 54, 55]. More recently, new trials with careful selection of patients have demonstrated clear benefits of NIV [56-58]. 


\section{Continuous positive airway pressure}

A recent investigation evaluated whether CPAP via a face mask produced physiological benefits and reduced the need for ETI in patients with acute lung injury [59]. CPAP was associated with an early favourable physiological response in terms of comfort and oxygenation during the first hour. However, no differences were found in the need for ETI, inhospital mortality or duration of ICU stay. In addition, use of CPAP was associated with more complications, including stress ulcer bleeding and cardiac arrest at the time of ETI. These results suggest that CPAP alone cannot be recommended for avoiding ETI in patients with acute lung injury. Its use should be limited to a short initial period if no other method is available.

\section{Pressure support and positive end-expiratory pressure}

Until the late 1990s, the most convincing successes with NIV were obtained in patients with acute respiratory acidosis in whom hypoxaemia was not the main reason for respiratory failure. One randomised controlled trial, of WYSOCKI et al. [55], found no benefit of NIV in patients with no previous history of chronic lung disease, except in the subgroup of patients who developed acute hypercapnia. However, the beneficial effects of NIV have now been extended to different forms of hypoxaemic respiratory failure with carefully selected patients, showing that NIV may reduce the need for ETI and improve outcomes [26, 56-58, 60, 61]. ANTONELLI et al. [56] showed marked benefits of NIV using pressure support and PEEP in hypoxaemic patients free from COPD, haemodynamic instability or neurological impairment, who were randomised when they reached predefined criteria for ETI. Improvements in oxygenation were similar with both the noninvasive and the invasive approach. Despite a 30\% failure rate, patients treated with NIV showed a shorter duration of ventilation and ICU stay and experienced fewer complications. Thus NIV can be effective in selected patients with hypoxaemic respiratory failure but with no haemodynamic or mental impairment.

\section{Immunosuppressed patients}

One of the main benefits of NIV may be a reduction in the risk of infectious complications $[5,6]$. Therefore, patients at high risk of nosocomial infection when mechanically ventilated may be particularly likely to benefit from NIV. Several recent trials have shown major benefits of NIV as a preventive measure during episodes of acute hypoxaemic respiratory failure in solid organ transplant patients or patients with severe immunosuppression, particularly related to haematological malignancies and neutropenia [57, 60,62]. The rates of ETI and infectious complication, duration of stay, and mortality were significantly reduced by use of NIV. Early initiation of NIV seems necessary to avoid ETI and provide benefit to patients.

Patients suffering from Pneumocystis carinii pneumonia during the course of human immunodeficiency virus infection may also benefit from NIV, as shown in the case/control study of CONFALONIERI et al. [63]

\section{Lung surgery}

Several studies looked at the use of NIV after lung surgery [64-66]. AURIANT et al. [64] conducted a randomised controlled trial in patients who experienced respiratory distress after lung resection. The reason why ETI should be avoided is the very poor outcome of patients, who usually require reintubation shortly after lung surgery. A reduction in ETI rate and a clear benefit in terms of hospital survival was observed with NIV. A noncontrolled study suggested interesting results using NIV after bilateral lung transplantation [65].

\section{Community-acquired pneumonia}

CONFALONIERI et al. [26], in a randomised controlled trial, showed major benefit of NIV in patients with communityacquired pneumonia, by reducing the rate of ETI and complications and duration of stay. This benefit, however, was almost entirely explained by the subgroup of patients with COPD. Other studies with severely hypoxaemic patients with pneumonia have shown a high rate of failure in this subgroup [27, 32, 67]. NIV cannot be recommended for all patients with severe community-acquired pneumonia.

\section{Noninvasive ventilation in the postextubation period}

The physiological rationale for this approach was recently demonstrated by VitacCA et al. [68]. HilberT et al. [69] suggested favourable effects of NIV on preventing reintubation in patients with COPD in a case/control study. A recent prospective randomised trial by KEENAN et al. [70] was performed in all patients experiencing postextubation respiratory distress. This study did not show any benefit of NIV. Two other prospective randomised trials did not find any preventive effect of NIV [71, 72]. The benefits of this technique may thus be observed only in patients with COPD, and the efficacy of NIV in preventing reintubation in all patients remains unproven.

A number of patients with COPD still require ETI because they fail NIV, show a contraindication to NIV (such as a need for surgery) or exhibit criteria requiring immediate ETI. However, when there is a need for prolonged ventilatory assistance, these patients may be switched to NIV after a few days of ETI, as a means of deliberately reducing the duration of invasive ventilation [22, 23]. This approach was shown, in two randomised controlled trials, to reduce the duration of ETI $[22,23]$. In one study only, complications were reduced and survival rate was higher at day 60 with this approach [22]. Lastly, NIV can also be proposed in persistent weaning failure. FERRER et al. [73] recently reported the results of a prospective randomised controlled trial in 43 mechanically ventilated patients who had failed a weaning trial for 3 consecutive days and were randomly extubated, receiving NIV, or remained intubated following a conventional weaning approach. Earlier extubation with NIV resulted in a shorter duration of mechanical ventilation and stay, less need for tracheotomy, a lower incidence of complications and improved survival in these patients.

\section{Patients not to be intubated}

Several reports have described the effects of NIV in patients with acute respiratory failure who were poor candidates for ETI because of advanced age, debilitation or a "do not resuscitate" order [74, 75]. The overall success rate in these reports was $\sim 60-70 \%$. Gas exchange improved rapidly in successfully treated patients. Even when respiratory failure 
did not resolve, NIV provided symptomatic relief from dyspnoea.

\section{Noninvasive ventilation during fibreoptic bronchoscopy}

Several studies have suggested or demonstrated that fibreoptic bronchoscopy could be performed during delivery of NIV (CPAP for hypoxaemic patients or pressure support plus PEEP), and that this approach improved tolerance of bronchoscopy and could prevent subsequent complications and the need for ETI [76, 77].

\section{Conclusion}

The success of noninvasive ventilation is dependent on various clinical aspects and the organisation of care, but also on a lot of technical issues. Far from being details, they can make a large difference [1,78]. They include the patient/ ventilator interface [79-81], type of humidifier [8] and ventilator used and its capabilities for triggering and pressurisation $[30,82,83]$. The general care of the patient is different from that for a patient receiving invasive ventilation, and will thus potentially greatly influence the success of the technique. There is now a good evidence base for the use of noninvasive ventilation in numerous different conditions and settings; however, it remains a complementary therapy to invasive ventilation and clinicians need to be aware of the contraindications.

\section{References}

1. Mehta S, Hill NS. Noninvasive ventilation. Am J Respir Crit Care Med 2001; 163: 540-577.

2. Peter JV, Moran JL, Phillips-Hughes J, Warn D. Noninvasive ventilation in acute respiratory failure - a meta-analysis update. Crit Care Med 2002; 30: 555-562.

3. Lightowler JV, Wedzicha JA, Elliott MW, Ram FS. Noninvasive positive pressure ventilation to treat respiratory failure resulting from exacerbations of chronic obstructive pulmonary disease: Cochrane systematic review and metaanalysis. BMJ 2003; 326: 185-187.

4. Carlucci A, Richard J-C, Wysocki M, Lepage E, Brochard L, and the Société de Réanimation de Langue Française Collaborative Group on Mechanical Ventilation. Noninvasive versus conventional mechanical ventilation. An epidemiological survey. Am J Respir Crit Care Med 2001; 163: 874-880.

5. Nourdine K, Combes P, Carton M-J, Beuret P, Cannamela A, Ducreux J-C. Does noninvasive ventilation reduce the ICU nosocomial infection risk? A prospective clinical survey. Intensive Care Med 1999; 25: 567-573.

6. Girou E, Schortgen F, Delclaux C, et al. Association of noninvasive ventilation with nosocomial infections and survival in critically ill patients. JAMA 2000; 284: 2361-2367.

7. Carrey Z, Gottfried SB, Levy RD. Ventilatory muscle support in respiratory failure with nasal positive pressure ventilation. Chest 1990; 97: 150-158.

8. Lellouche F, Maggiore SM, Deye N, et al. Effect of the humidification device on the work of breathing during noninvasive ventilation. Intensive Care Med 2002; 28: 15821589 .

9. Brochard L, Isabey D, Piquet $\mathrm{J}$, et al. Reversal of acute exacerbations of chronic obstructive lung disease by inspiratory assistance with a face mask. N Engl J Med 1990; 323: $1523-1530$.

10. Brochard L. Pressure support ventilation. In: Tobin MJ, ed.
Principles and practice of mechanical ventilation. New York, Mac Graw-Hill, 1994; pp. 239-257.

11. Petrof BJ, Legaré M, Goldberg P, Milic-Emili J, Gottfried SB. Continuous positive airway pressure reduces work of breathing and dyspnea during weaning from mechanical ventilation in severe chronic obstructive pulmonary disease (COPD). Am Rev Resp Dis 1990; 141: 281-289.

12. Appendini L, Patessio A, Zanaboni S, et al. Physiologic effects of positive end-expiratory pressure and mask pressure support during exacerbations of chronic obstructive pulmonary disease. Am J Respir Crit Care Med 1994; 149: 1069-1076.

13. Vitacca M, Rubini F, Foglio K, Scalvani S, Nava S, Ambrosino N. Non invasive modalities of positive pressure ventilation improve the outcome of acute exacerbations in COLD patients. Intensive Care Med 1993; 19: 450-455.

14. Bott J, Carroll MP, Conway JH, et al. Randomised controlled trial of nasal ventilation in acute ventilatory failure due to chronic obstructive airways disease. Lancet 1993; 341: 1555-1557.

15. Kramer N, Meyer TJ, Meharg J, Cece RD, Hill NS. Randomized, prospective trial of noninvasive positive pressure ventilation in acute respiratory failure. Am J Respir Crit Care Med 1995; 151: 1799-1806.

16. Brochard L, Mancebo J, Wysocki M, et al. Noninvasive ventilation for acute exacerbations of chronic obstructive pulmonary disease. N Engl J Med 1995; 333: 817-822.

17. Barbé F, Togores B, Rubi M, Pons S, Maimo A, Agusti AGN. Noninvasive ventilatory support does not facilitate recovery from acute respiratory failure in chronic obstructive pulmonary disease. Eur Respir J 1996; 9: 1240-1245.

18. Angus RM, Ahmed AA, Fenwick LJ, Peacock AJ. Comparison of the acute effects on gas exchange of nasal ventilation and doxapram in acute excaerbations of chronic obstructive pulmonary disease. Thorax 1996; 51: 1048-1050.

19. Celikel T, Sungur M, Ceyhan B, Karakurt S. Comparison of noninvasive positive pressure ventilation with standard medical therapy in hypercapnic acute respiratory failure. Chest 1998; 114: 1636-1642.

20. Plant PK, Owen JL, Elliott MW. Early use of non-invasive ventilation for acute exacerbations of chronic obstructive pulmonary disease on general respiratory wards: a multicentre randomised controlled trial. Lancet 2000; 355: 19311935.

21. Conti G, Antonelli M, Navalesi P, et al. Noninvasive vs. conventional mechanical ventilation in patients with chronic obstructive pulmonary disease after failure of medical treatment in the ward: a randomized trial. Intensive Care Med 2002; 28: 1701-1707.

22. Nava S, Ambrosino $\mathrm{N}$, Clini $\mathrm{E}$, et al. Noninvasive mechanical ventilation in the weaning of patients with respiratory failure due to chronic obstructive pulmonary disease. A randomized, controlled trial. Ann Intern Med 1998; 128: 721-728.

23. Girault C, Daudenthun I, Chevron V, Tamion F, Leroy J, Bonmarchand G. Noninvasive ventilation as a systematic extubation and weaning technique in acute-on-chronic respiratory failure. Am J Respir Crit Care Med 1999; 160: 86-92.

24. Evans TW. International Consensus Conferences in Intensive Care Medicine: non-invasive positive pressure ventilation in acute respiratory failure. Intensive Care Med 2001; 27: 166-178.

25. Baudouin S, Blumenthal S, Cooper B, et al. Non-invasive ventilation in acute respiratory failure. Thorax 2002; 57: 192211.

26. Confalonieri M, Potena A, Carbone G, Della Porta R, Tolley EA, Meduri GU. Acute respiratory failure in patients with severe community-acquired pneumonia. A prospective randomised evaluation of non-invasive ventilation. $\mathrm{Am}$ J Respir Crit Care Med 1999; 160: 1585-1591.

27. Abou-Shala N, Meduri U. Noninvasive mechanical ventilation in patients with acute respiratory failure. Crit Care Med 1996; 24: 705-715. 
28. Fernandez M, Villagra A, Blanch L, Fernandez R. Non-invasive mechanical ventilation in status asthmaticus. Intensive Care Med 2001; 27: 486-492.

29. Wood KA, Lewis L, Von Harz B, Kollef MH. The use of noninvasive positive pressure ventilation in the emergency department: results of a randomized clinical trial. Chest 1998; 113: 1339-1346.

30. Nava S, Evangelisti I, Rampulla C, Compagnoni ML, Fracchia C, Rubini F. Human and financial costs of noninvasive mechanical ventilation in patients affected by COPD and acute respiratory failure. Chest 1997; 111: 16311638.

31. Brochard L. Non-invasive ventilation for acute exacerbations of COPD: a new standard of care. Thorax 2000; 55: $817-818$

32. Antonelli M, Conti G, Moro M, et al. Predictors of failure of noninvasive positive pressure ventilation in patients with acute hypoxemic respiratory failure: a multi-center study. Intensive Care Med 2001; 27: 1718-1728.

33. Confalonieri M, Parigi P, Scartabellati A, et al. Noninvasive mechanical ventilation improves the immediate and longterm outcome of COPD patients with acute respiratory failure. Eur Respir $J$ 1996; 9: 422-430.

34. Bardi G, Pierotello R, Desideri M, Valdisseri L, Bottai M, Palla A. Nasal ventilation in COPD exacerbations: early and late results of a prospective, controlled study. Eur Respir $J$ 2000; 15: 98-104.

35. Vitacca M, Clini E, Rubini F, Nava S, Foglio K, Ambrosino $\mathrm{N}$. Non-invasive mechanical ventilation in severe chronic obstructive lung disease and acute respiratory failure: short-and long-term prognosis. Intensive Care Med 1996; 22: $94-100$.

36. Drinker P, Shaw L. An apparatus for the prolonged administration of artificial respiration. J Clin Invest 1929; 7: 229.

37. Drinker P, McKhann C. The iron lung. First practical means of respiratory support. JAMA 1986; 225: 1476-1480.

38. Corrado A, Gorini M, Ginanni R, et al. Negative pressure ventilation versus conventional mechanical ventilation in the treatment of acute respiratory failure in COPD patients. Eur Respir J 1998; 12: 519-525.

39. Corrado A, Confalonieri M, Marchese S, et al. Iron lung vs mask ventilation in the treatment of acute on chronic respiratory failure in COPD patients: a multicenter study. Chest 2002; 121: 189-195.

40. Jolliet P, Tassaux D, Thouret JM, Chevrolet JC. Beneficial effects of helium: oxygen versus air: oxygen noninvasive pressure support in patients with decompensated chronic obstructive pulmonary disease. Crit Care Med 1999; 27: 2422-2429.

41. Jaber S, Fodil R, Carlucci A, et al. Noninvasive ventilation with helium-oxygen in acute exacerbations of chronic obstructive pulmonary disease. Am J Respir Crit Care Med 2000; 161: 1191-1200.

42. Räsänen J, Heikkilä J, Downs J, Nikki P, Vaisänen IT, Viitanen A. Continuous positive airway pressure by face mask in acute cardiogenic pulmonary edema. Am J Cardiol 1985; 55: 296-300.

43. Bersten AD, Holt AW, Vedig AE, Skowronski GA, Baggely CJ. Treatment of severe cardiogenic pulmonary edema with continuous positive airway pressure delivered by face mask. $N$ Engl J Med 1991; 325: 1825-1830.

44. Lin M, Yang YF, Chiang HT, Chang MS, Chiang BN, Cheitlin MD. Reappraisal of continuous positive airway pressure therapy in acute cardiogenic pulmonary edema. Short-term results and long-term follow-up. Chest 1995; 107: $1379-1386$.

45. Domenighetti G, Gayer R, Gentilini R. Noninvasive pressure support ventilation in non-COPD patients with acute cardiogenic pulmonary edema and severe communityacquired pneumonia: acute effects and outcome. Intensive Care Med 2002; 28: 1226-1232.

46. Lenique F, Habis M, Lofaso F, Dubois-Randé JL, Harf A,
Brochard L. Ventilatory and hemodynamic effects of continuous positive airway pressure in left heart failure. Am J Respir Crit Care Med 1997; 155: 500-505.

47. Masip J, Betbese AJ, Paez J, et al. Non-invasive pressure support ventilation versus conventional oxygen therapy in acute cardiogenic pulmonary oedema: a randomised trial. Lancet 2000; 356: 2126-2132.

48. L'Her E, Moriconi M, Texier F, et al. Non-invasive continuous positive airway pressure in acute hypoxaemic respiratory failure - experience of an emergency department. Eur J Emerg Med 1998; 5: 313-318.

49. Hoffmann B, Welte T. The use of noninvasive pressure support ventilation for severe respiratory insufficiency due to pulmonary oedema. Intensive Care Med 1999; 25: 15-20.

50. Rusterholtz $\mathrm{T}$, Kempf $\mathrm{J}$, Berton $\mathrm{C}$, et al. Noninvasive pressure support ventilation (NIPSV) with face mask in patients with acute cardiogenic pulmonary edema (ACPE). Intensive Care Med 1999; 25: 21-28.

51. Mehta S, Gregory DJ, Woolard RH, et al. Randomized, prospective trial of bilevel versus continuous positive airway pressure in acute pulmonary edema. Crit Care Med 1997; 25: 620-628.

52. Sharon A, Shpirer I, Kaluski E, et al. High-dose intravenous isosorbide-dinitrate is safer and better than Bi-PAP ventilation combined with conventional treatment for severe pulmonary edema. J Am Coll Cardiol 2000; 36: 832-837.

53. Ashbaugh DG, Bigelow DB, Petty TL, Levine BE. Acute respiratory distress in adults. Lancet 1967; 2: 319-323.

54. Meduri GU, Conoscenti CC, Menashe P, Nair S. Noninvasive face mask ventilation in patients with acute respiratory failure. Chest 1989; 95: 865-870.

55. Wysocki M, Tric L, Wolff MA, Millet H, Herman B. Noninvasive pressure support ventilation in patients with acute respiratory failure. A randomized comparison with conventional therapy. Chest 1995; 107: 761-768.

56. Antonelli M, Conti G, Rocco M, et al. A comparison of noninvasive positive-pressure ventilation and conventional mechanical ventilation in patients with acute respiratory failure. $N$ Engl J Med 1998; 339: 429-435.

57. Antonelli M, Contin G, Bufi M, et al. Noninvasive ventilation for treatment of acute respiratory failure in patients undergoing solid organ transplantation. A randomized trial. JAMA 2000; 283: 235-241.

58. Martin TJ, Hovis JD, Costantino JP, et al. A randomized, prospective evaluation of noninvasive ventilation for acute respiratory failure. Am J Respir Crit Care Med 2000; 161: 807-813.

59. Delclaux C, L'Her E, Alberti C, et al. Treatment of acute hypoxemic nonhypercapnic respiratory insufficiency with continuous positive airway pressure delivered by a face mask. A randomized controlled trial. JAMA 2000; 284: 2352-2360.

60. Hilbert G, Gruson D, Vargas F, et al. Noninvasive ventilation in immunosuppressed patients with pulmonary infiltrates, fever, and acute respiratory failure. $N \mathrm{Engl} \mathrm{J} \mathrm{Med}$ 2001; 344: 481-487.

61. Rocker G, Mackenzie M, Williams B, Logan P. Noninvasive positive pressure ventilation: successful outcome in patients with acute lung injury/ARDS. Chest 1999; 115: 173-177.

62. Azoulay E, Alberti C, Bornstain C, et al. Improved survival in cancer patients requiring mechanical ventilatory support: impact of noninvasive mechanical ventilatory support. Crit Care Med 2001; 29: 519-525.

63. Confalonieri M, Calderini E, Terraciano S, et al. Noninvasive ventilation for treating acute respiratory failure in AIDS patients with Pneumocystis carinii pneumonia. Intensive Care Med 2002; 28: 1233-1238.

64. Auriant I, Jallot A, Herve P, et al. Noninvasive ventilation reduces mortality in acute respiratory failure following lung resection. Am J Respir Crit Care Med 2001; 164: 1231-1235.

65. Rocco M, Conti G, Antonelli M, et al. Non-invasive pressure support ventilation in patients with acute respiratory failure 
after bilateral lung transplantation. Intensive Care Med 2001; 27: $1622-1626$.

66. Aguilo R, Togores B, Pons S, Rubi M, Barbe F, Agusti AG. Noninvasive ventilatory support after lung resectional surgery. Chest 1997; 112: 117-121.

67. Jolliet P, Abajo B, Pasquina P, Chevrolet J-C. Non-invasive pressure support ventilation in severe community-acquired pneumonia. Intensive Care Med 2001; 27: 812-821.

68. Vitacca M, Ambrosino N, Clini E, et al. Physiological response to pressure support ventilation delivered before and after extubation in patients not capable of totally spontaneous autonomous breathing. Am J Respir Crit Care Med 2001; 164: 638-641.

69. Hilbert G, Gruson D, Portel L, Gbikpi-Benissan G, Cardinaud JP. Noninvasive pressure support ventilation in COPD patients with postextubation hypercapnic respiratory insufficiency. Eur Respir J 1998; 11: 1349-1353.

70. Keenan S, Powers C, McCormack D, Block G. Noninvasive positive-pressure ventilation for postextubation respiratory distress: a randomized controlled trial. JAMA 2002; 287: $3238-3244$.

71. Jiang JS, Kao SJ, Wang SN. Effect of early application of biphasic positive airway pressure on the outcome of extubation in ventilator weaning. Respirology 1999; 4: 161-165.

72. Kilger E, Briegel J, Haller M, et al. Effects of noninvasive positive pressure ventilatory support in non-COPD patients with acute respiratory insufficiency after early extubation. Intensive Care Med 1999; 25: 1374-1380.

73. Ferrer M, Esquinas A, Arancibia F, et al. Noninvasive ventilation during persistent weaning failure: a randomized controlled trial. Am J Respir Crit Care Med 2003; 168: 70-76.

74. Meduri GU, Fox RC, Abou-Shala N, Leeper KV, Wunderink RG. Noninvasive mechanical ventilation via face mask in patients with acute respiratory failure who refused endotracheal intubation. Crit Care Med 1994; 22: 1584-1590.

75. Benhamou D, Girault C, Faure C, Portier F, Muir JF. Nasal mask ventilation in acute respiratory failure. Experience in elderly patients. Chest 1992; 102: 912-917.

76. Antonelli M, Conti G, Riccioni L, Meduri GU. Noninvasive positive-pressure ventilation via face mask during bronchoscopy with BAL in high-risk hypoxemic patients. Chest 1996; 110: 724-728.

77. Maitre B, Jaber S, Maggiore S, et al. Continuous positive airway pressure during fiberoptic brochoscopy in hypoxemic patients. A randomized double-blind study using a new device. Am J Respir Crit Care Med 2000; 162: 1063-1067.

78. Brochard L. What is really important to make non-invasive ventilation work. Crit Care Med 2000; 28: 2139-2140.

79. Navalesi P, Fanfulla F, Frigerio P, Gregoretti C, Nava S. Physiologic evaluation of noninvasive mechanical ventilation delivered with three types of masks in patients with chronic hypercapnic respiratory failure. Crit Care Med 2000; 28: $1785-1790$.

80. Schettino GP, Tucci MR, Sousa R, Valente Barbas CS, Passos Amato MB, Carvalho CR. Mask mechanics and leak dynamics during noninvasive pressure support ventilation: a bench study. Intensive Care Med 2001; 27: 1887-1891.

81. Hill NS. Saving face: better interfaces for noninvasive ventilation. Intensive Care Med 2002; 28: 227-229.

82. Richard JC, Carlucci A, Breton L, et al. Bench testing of pressure support ventilation with three different generations of ventilators. Intensive Care Med 2002; 28: 1049-1057.

83. Tassaux D, Strasser S, Fonseca S, Dalmas E, Jolliet P. Comparative bench study of triggering, pressurization, and cycling between the home ventilator VPAP II and three ICU ventilators. Intensive Care Med 2002; 28: 1254 1261. 